\title{
State and Local Clean Energy Policy Primer: Getting from Here to Clean Electricity with Policy
}

\section{Introduction}

Single policies do not create market transformation for a clean energy economy in states and localities. To reap the economic, environmental, and security benefits of clean energy development, suites of policies applied in succession are often the most cost-effective way to move toward transformation. This also allows for states and localities to target the lowest cost strategies first, increasing consumer comfort with innovative clean energy technologies later on.

This factsheet proposes a framework for how states and localities can build policy portfolios by first setting the stage for clean energy in the market with low cost policies, and then growing the market with successive policies until the need for financial incentives can be reduced and eventually eliminated.

Figure 1 provides a visual of the suggested framework for policy development at the state and local level. The overall concept is to build on the foundation of market creation policies, and then later move into the development of more advanced policies.

\section{Barriers Addressed}

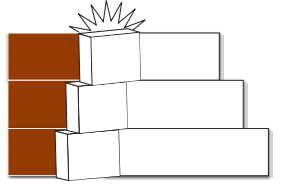

By following this framework, states and localities can overcome the most basic barriers first and then move onto advanced barriers. Primary policy barriers include:

\section{Initial Barriers}

- Owner/Renter (Principal/Agent) Challenge

- Disincentives for Energy Efficiency Implementation

- Access to the Electricity Grid

\section{Intermediate Barriers \\ - Investor Uncertainty \\ - Lack of Market \\ - Public Understanding}

\section{Advanced Barriers}

- Technology First Cost

- Investment Uncertainty

Figure 1. Framework for using policy to transform energy markets. Figure by Anthony Castellano, NREL

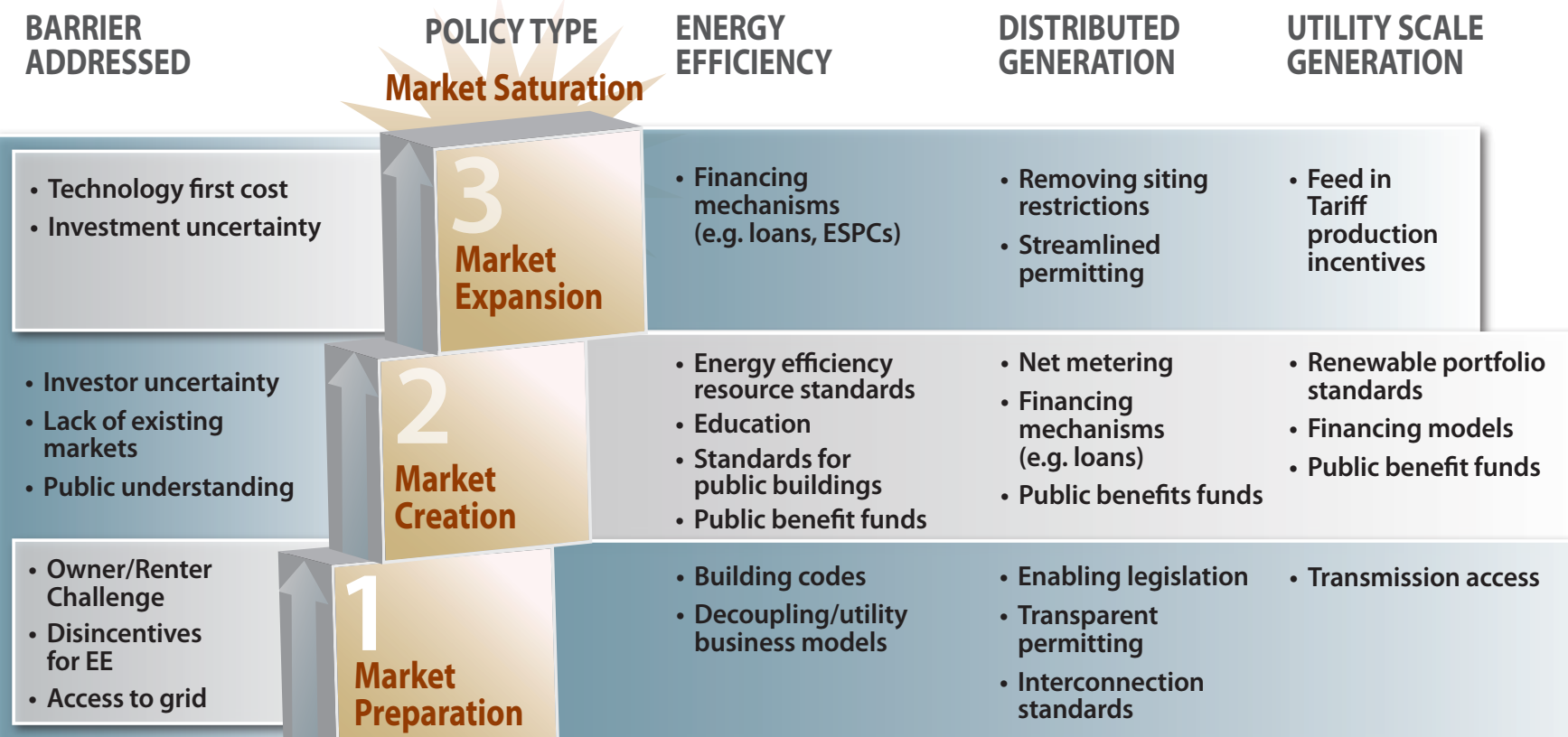




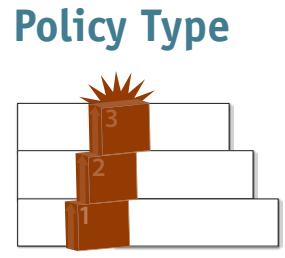

In this framework, policies are grouped by how they overcome barriers as well as the type of clean energy strategy they refer to because different policy

strategies apply to different goals.

For example, if the policy goal is to save energy, energy efficiency policies are good options. If a community or state wishes to promote renewable energy development on the customer side of the meter, policies might focus on distributed generation technologies. In states and communities with generation needs, policies that support larger scale generation can be specifically designed.

For each type of technology goal, the policies are grouped as to how they overcome barriers. The steps toward clean energy are defined as:

Market Preparation: Policies that are designed to allow the market to use energy efficiency and renewable energy technologies. Typically, these policies remove legacy or institutional barriers to ease implementation of advanced technologies.

Market Creation: Policies that facilitate the uptake of energy efficiency and renewable energy technologies in the market. These policies go beyond preparing the market into driving market demand for clean energy by:

- using mandates to assure investors that the market for the technology is certain to exist over the long term

- establishing programmatic financing mechanisms.

Market Expansion: Policies that overcome the first cost barriers to clean energy development. These policies often take the form of financial and other incentives.

Market Saturation: Policies that streamline market preparation and creation to ensure markets going forward. In this stage, it is expected that institutional barriers have been removed and enough markets have been created and expanded into, and as a result, technologies have matured and costs have been reduced enough to decrease the need for financial incentives.

The policies listed here and in Figure 1 are examples of the types that fit within each block of the framework.

\section{Energy Efficiency, Distributed Generation, and Utility Scale Generation}

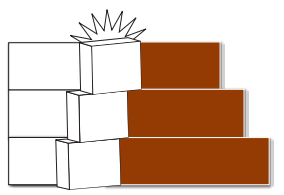

Likewise, policies differ in how they apply to different mixes of technologies (e.g. energy efficiency, distributed renewable energy, utility scale renewable energy). As a result, each jurisdiction needs to identify policies that will work within each category for the development of the resources they are targeting. For that purpose, the framework separates the types of policies that apply to different technological focuses.

\section{Now that Policies are Identified....}

Policy design and implementation are critical to the success of overcoming specific barriers. There are multiple resources for identifying policy best practices and options for implementation that can be tailored to specific jurisdictional differences, including:

\section{Environmental Protection Agency Clean Energy-} Environment Guide to Action. Provides examples and implementation suggestions for different state and local policies. www.epa.gov/statelocalclimate/resources/ action-guide.html.

\section{U.S. Department of Energy (DOE) Solar America Cities} Guide for Local Governments. Provides an overview of a wide variety of local-level clean energy policy strategies, provided by DOE's Solar Program's Solar America Communities Initiative. www.solaramericacommunities.energy.gov/resources/ guide_for_local_governments/

Clean Energy Policy Analysis Website. This DOE- funded project provides information on a wide variety of policies, including a policy choice decision tool for policymakers. Examples of different policies and how states and localities have implemented them are available here. www.nrel.gov/cepa.

\section{Getting Help}

Direct technical assistance programs can provide further tailoring and answers to more detailed questions. NREL manages a number of technical assistance efforts for states and localities. Access them all by sending a request to tech.assist@nrel.gov.

State and local officials can get help in assessing their jurisdiction's policy strengths and opportunities, identifying policies that work for their specific goals and needs, and assistance in evaluating policy effectiveness.
National Renewable Energy Laboratory 1617 Cole Boulevard, Golden, Colorado 80401 303-275-3000 • www.nrel.gov

Printed with a renewable-source ink on paper containing at least $50 \%$ wastepaper, including $10 \%$ post consumer waste.
NREL is a national laboratory of the U.S. Department of Energy Office of Energy Efficiency and Renewable Energy Operated by the Alliance for Sustainable Energy, LLC

NREL/FS-7A30-51319・April 2011 